\title{
Methodology of a diabetes prevention translational research project utilizing a community-academic partnership for implementation in an underserved Latino community
}

\author{
Philip A Merriam*1, Trinidad L Tellez ${ }^{2}$, Milagros C Rosal ${ }^{1}$, \\ Barbara C Olendzki ${ }^{1}$, Yunsheng Ma ${ }^{1}$, Sherry L Pagoto ${ }^{1}$ and Ira S Ockene ${ }^{3}$
}

\begin{abstract}
Address: ${ }^{1}$ Division of Preventive and Behavioral Medicine, Department of Medicine, University of Massachusetts Medical School, Worcester, MA, USA, ${ }^{2}$ Greater Lawrence Family Health Center, Lawrence, MA and Department of Family Medicine and Community Health, University of Massachusetts Medical School, Worcester, MA, USA and ${ }^{3}$ Division of Cardiovascular Medicine, Department of Medicine, University of Massachusetts Medical School, Worcester, MA, USA

Email: Philip A Merriam* - Philip.Merriam@umassmed.edu; Trinidad L Tellez - TTellez@glfhc.org; Milagros C Rosal - Milagros.Rosal@umassmed.edu; Barbara C Olendzki - Barbara.Olendzki@umassmed.edu; Yunsheng Ma - Yunsheng.Ma@umassmed.edu; Sherry L Pagoto - Sherry.Pagoto@umassmed.edu; Ira S Ockene - Ira.Ockene@umassmed.edu * Corresponding author
\end{abstract}

Published: 13 March 2009

BMC Medical Research Methodology 2009, 9:20 doi:10.1 186/147।-2288-9-20

This article is available from: http://www.biomedcentral.com/I47I-2288/9/20

(c) 2009 Merriam et al; licensee BioMed Central Ltd.

This is an Open Access article distributed under the terms of the Creative Commons Attribution License (http://creativecommons.org/licenses/by/2.0), which permits unrestricted use, distribution, and reproduction in any medium, provided the original work is properly cited.
Received: 4 November 2008

Accepted: 13 March 2009

\begin{abstract}
Background: Latinos comprise the largest racial/ethnic group in the United States and have 2-3 times the prevalence of type 2 diabetes mellitus as Caucasians.

Methods and design: The Lawrence Latino Diabetes Prevention Project (LLDPP) is a community-based translational research study which aims to reduce the risk of diabetes among Latinos who have $a \geq 30 \%$ probability of developing diabetes in the next 7.5 years per a predictive equation. The project was conducted in Lawrence, Massachusetts, a predominantly Caribbean-origin urban Latino community. Individuals were identified primarily from a community health center's patient panel, screened for study eligibility, randomized to either a usual care or a lifestyle intervention condition, and followed for one year. Like the efficacious Diabetes Prevention Program (DPP), the LLDPP intervention targeted weight loss through dietary change and increased physical activity. However, unlike the DPP, the LLDPP intervention was less intensive, tailored to literacy needs and cultural preferences, and delivered in Spanish. The group format of the intervention (I 3 group sessions over I year) was complemented by 3 individual home visits and was implemented by individuals from the community with training and supervision by a clinical research nutritionist and a behavioral psychologist. Study measures included demographics, Stern predictive equation components (age, gender, ethnicity, fasting glucose, systolic blood pressure, HDLcholesterol, body mass index, and family history of diabetes), glycosylated hemoglobin, dietary intake, physical activity, depressive symptoms, social support, quality of life, and medication use. Body weight was measured at baseline, 6-months, and one-year; all other measures were assessed at baseline and one-year. All surveys were orally administered in Spanish.
\end{abstract}

Results: A community-academic partnership enabled the successful recruitment, intervention, and assessment of Latinos at risk of diabetes with a one-year study retention rate of $93 \%$.

Trial registration: $\mathrm{NCT} 00810290$ 


\section{Background}

Latinos are the largest minority group in the United States representing $13.7 \%$ of the total population [1]. The Centers for Disease Control analyzed data from the Behavioral Risk Factor Surveillance System (BRFSS) and found that Hispanics continue to have a higher prevalence of diabetes than non-Hispanic whites [2]. Overall, $7.4 \%$ of Hispanics in the BRFSS had been told by a doctor that they had diabetes. Given the increasing prevalence of sedentary lifestyle and obesity and their correlation with diabetes and heart disease $[3,4]$, it is likely that the number of individuals with type 2 diabetes mellitus will continue to increase, and that this will be an especially significant burden among Latino communities. Latinos have a very high risk of developing diabetes in their lifetime - a 50\% probability for Hispanic women, compared to the approximately 1 in 3 chance for the average American, making primary prevention of type 2 diabetes an important priority in this population [5].

The Diabetes Prevention Program (DPP) was a randomized clinical trial that successfully demonstrated that modest weight loss and increased physical activity could reduce the incidence of diabetes in a group of pre-diabetic patients by $58 \%$ [6]. However, both the recruitment methodology and the intervention were very costly. The trial included 27 centers recruiting approximately 1 participant/center/week over a 3 year period at a cost (excluding staff) of approximately $\$ 1075$ per randomized participant [7]. The DPP intervention began with 16 weekly one-hour individual intervention sessions carried out over 24-weeks and continued with monthly individual and group sessions [7]. The methodology used in the DPP may be too expensive to implement in real world settings, requiring less expensive methods to be developed and tested $[8,9]$.

The primary objective of the Lawrence Latino Diabetes Prevention Project (LLDPP) is to design and test a less intensive intervention that, like the DPP, targets weight loss through dietary change and increased physical activity, in order to reduce the risk of type 2 diabetes in a lowincome Latino community. The LLDPP study methodology was designed to decrease the high cost of screening and recruitment seen in the DPP, in part by using an accurate but inexpensive screening procedure based on a predictive equation that weights age, gender, ethnicity, fasting blood glucose (FBG), systolic blood pressure, high density lipoprotein (HDL-C), body mass index (BMI), and natal family history of diabetes to estimate relative risk of developing diabetes in the subsequent 7.5 years [10]. See Figure 1 for Stern formula.

The purpose of this paper is to present the methodology used to translate the DPP program to a diabetes-prevention research project in a high-risk Latino community, and to highlight the community-academic partnership formed to carry this out.

\section{Methods and design Setting}

This project was carried out in the city of Lawrence, Massachusetts, a primarily Latino community characterized by families struggling with high levels of poverty, limited access to jobs, and limited access to resources families need to prosper [11].

\section{Community and academic collaborators}

Study planning and implementation involved collaboration among the Greater Lawrence Family Health Center (GLFHC), the Lawrence Council on Aging (LCOA)/Senior Center, the YWCA of Greater Lawrence, and investigators from 2 campuses of the University of Massachusetts (UMass). As the study progressed, the Mayor's Health Task Force joined the partnership. The study principal investigator (PI) and a co-PI are UMass Medical School (UMMS) faculty, and the community-PI is a Greater Lawrence Family Health Center (GLFHC) physician and UMMS faculty member. The PI is also a UMass Memorial Medical Center (UMMMC) physician.

The GLFHC provides healthcare to approximately $80 \%$ of the Lawrence Latino population. The health center houses a UMMS-affiliated Family Medicine Residency program and a CDC-funded Racial and Ethnic Approaches to Community Health (REACH) diabetes disparities reduction project. The study administrative support for this project was based at GLFHC under the direction of the community-PI, who bridged the partnership among the 6 community and academic collaborators.

The Lawrence Council on Aging (LCOA)/Senior Center, a conveniently located and well-respected social service facility, housed all study screening, recruitment, and assessment appointments. The LCOA and YWCA each provided a community coordinator to staff the study through subcontract arrangements. The community coordinators were chosen for being well-known, respected, and having longstanding relationships and community work experience within the community of Lawrence. Figure 2 presents the study partnership diagram.

\section{Study management}

The partners in this collaboration maintained formal communication through thrice-yearly meetings held at the Lawrence Senior Center, and also informally through regular telephone contacts and e-mail. The study staff was divided into a recruitment/retention team and an intervention team; both teams met monthly. The project director, community-PI, and lead nutritionist shared responsibility for team oversight. The project director, a 


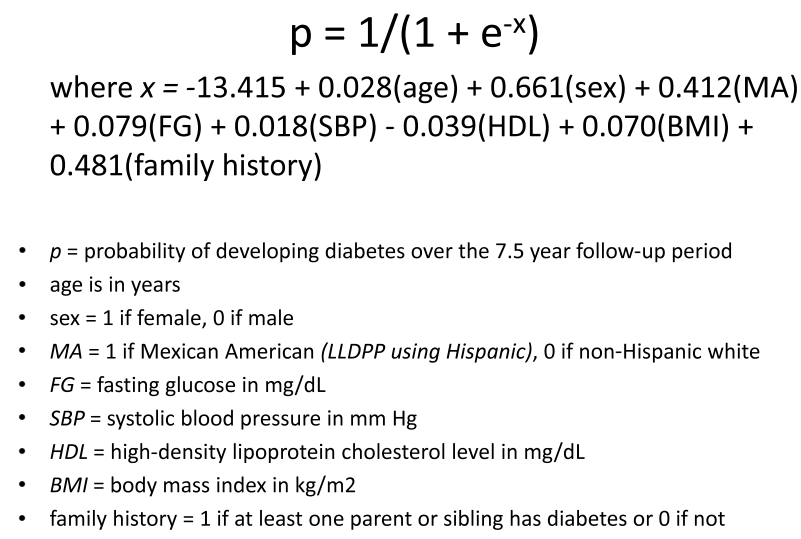

- $p=$ probability of developing diabetes over the 7.5 year follow-up period

- age is in years

- $\operatorname{sex}=1$ if female, 0 if male

- $M A=1$ if Mexican American (LLDPP using Hispanic), 0 if non-Hispanic white

- $F G=$ fasting glucose in $\mathrm{mg} / \mathrm{dL}$

- $S B P=$ systolic blood pressure in $\mathrm{mm} \mathrm{Hg}$

- $H D L=$ high-density lipoprotein cholesterol level in $\mathrm{mg} / \mathrm{dL}$

- $B M I=$ body mass index in $\mathrm{kg} / \mathrm{m} 2$

- family history $=1$ if at least one parent or sibling has diabetes or 0 if not

\section{Figure I}

Stern formula.

UMMS faculty member with a background in research management and social work, had primary responsibility for the smooth operation of the study on a day-to-day basis, visiting the clinic at least weekly to meet with study staff, and coordinating the two monthly team meetings. The community-PI, a practicing Latina physicianresearcher who was responsible for bridging the community-academic partnership, oversaw the local administrative operations and met regularly with the recruitment/ retention team. The lead clinical research nutritionist, who had worked with the co-PI Latina behavioral psychologist to design and develop the intervention materials and train the community intervention team, also met regularly with them $[12,13]$. Daily management of study activities was facilitated by the use of Lotus Notes/IBM tracking system software (Lotus Notes R5.0.11 ${ }^{\circledR}$ ). The database was kept on a server at UMMS which could be accessed easily by study personnel in Lawrence and at UMass. Multiple levels of password protection were used to ensure data security.

\section{Recruitment and community outreach}

The primary recruitment outreach method entailed drawing from the GLFHC patient panel by identifying potentially eligible patients who received a mailed letter of invitation, and then telephone recruitment calls from the study community coordinators. A mailing list was generated every 6 to 8 weeks by running a screening query of the current GLFHC database to identify potentially eligible Latino patients with an age $\geq 25$ years who had a high likelihood of meeting eligibility criteria (e.g., overweight, history of hypertension, low HDL-C, or FBG 100-125 mg/ $\mathrm{dl}$, and not diabetic). A 2nd query was run to remove patients who had already been approached to be in the study; with approximately 250 names randomly selected for each mailing. Personalized patient screening invitation letters were created, signed by the patient's primary care physician (PCP) and the community-PI, and then mailed. Patients were eliminated by their PCPs if deemed ineligible or a poor study candidate (such as having severe psychiatric illness, etc.). PCPs were kept engaged through regular updates at provider meetings and through communications by the community-PI. The selected GLFHC patient names were downloaded into the Lotus Notes tracking database, and divided equally between the two community coordinators for subsequent telephone outreach.

Additional outreach methods included public service announcements on public access television, guest spots on local Spanish radio programs, advertisements in the local Spanish and bilingual newspapers, flier inserts in the Senior Center newsletter, and mailings to non-GLFHC physicians with the purpose of creating awareness of the study.

\section{Telephone pre-screening}

Pre-screening activities were conducted by each community coordinator who followed up on the mailed invitation letters with telephone calls two weeks after the mailing, unless an individual had already responded and declined further contact. The latter occurred rarely.

The initial telephone contact included an assessment of preliminary eligibility, an invitation to schedule a fasting screening appointment, and if scheduled, instruction to bring in all current medications. Reminder calls were made to patients the day before, and/or the morning of, all scheduled appointments.

\section{Screening appointment}

In addition to those patients scheduled for screening appointments as described above, patients were also screened as walk-ins if they learned of a screening event via word-of-mouth or community outreach.

Following a screening protocol, a community coordinator would explain the study, highlight what would occur at the visit, and obtain a signed screening consent form which was available in English and Spanish. Individuals then were administered a one-page survey which assessed diabetes risk perceptions, and underwent the study screening. All current medications were recorded, and anthropometric measures were taken by the clinic assistant. These included height and weight (without shoes and outerwear), blood pressure (after sitting quietly for $2 \mathrm{~min}$ utes) using the Dinamap $\mathrm{XL}^{\oplus}$ automated BP monitor, and a fasting fingerstick lipid profile and glucose measure (Cholestech LDX System ${ }^{\circledast}$ ).

The Stern predictive formula value and BMI were calculated using a Microsoft Excel ${ }^{\varpi}$ program. The community 


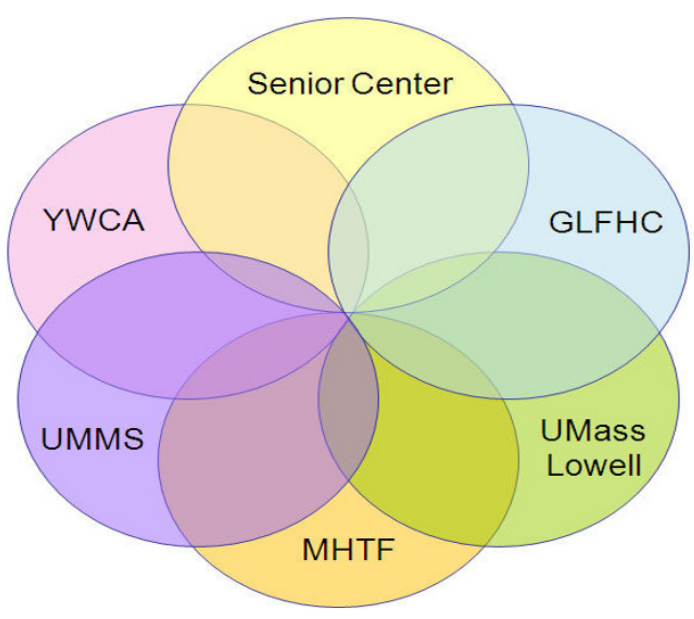

Figure 2

Study partners.

coordinator informed the screened individual of the results of their blood pressure, FBG, weight and BMI, total cholesterol and HDL-C, both verbally and in writing (written into a brief educational brochure), and their potential study eligibility. Patients were informed that their PCP would be receiving the results directly, and were encouraged to review their results with their PCP.

Those Latino individuals who were $\geq 25$ years of age, had a BMI $\geq 24 \mathrm{~kg} / \mathrm{m}^{2}$ and a $\geq 30 \%$ likelihood of developing diabetes in 7.5 years as predicted by the Stern equation were determined to be pre-eligible and invited to schedule a baseline appointment in 3-4 weeks. Each pre-eligible individual's PCP was mailed a medical clearance form that reviewed the eligibility criteria, and asked for the PCP's permission for the individual to participate.

Through screening or the PCP medical clearance form, the following criteria defined an ineligible state: a fasting glucose of $126 \mathrm{mg} / \mathrm{dL}$ or greater, inability or unwillingness to give informed consent, clinically diagnosed diabetes, a plan to move out of the area within the study period, presence of a psychiatric illness which limits ability to participate, no telephone, inability to walk unaided or walk five city blocks (1/4 mile) without stopping, having a medical condition likely to limit lifespan, taking a medication or having a medical condition that interfered with the assessment for diabetes, or having an endocrine disorder that alters blood sugar. In addition to asking these questions on the medical clearance form, all pre-eligible individuals' medication lists and screening flow-sheets were reviewed by the community-PI for study contraindications which included beta-blocking agents (not at stable dose for 3 months or more), thiazide diuretics at doses higher than $25 \mathrm{mg} /$ day, niacin in pharmacologic doses, systemic glucocorticoids, protease inhibitors, atypical antipsychotic agents (not at stable dose for 6 months or more), or prescription weight loss medications.

Nine hundred and forty-nine individuals had screening appointments during the screening phase which spanned 34 months, beginning on October 10, 2004.

\section{Baseline and follow-up assessments}

Recruitment into the study occurred at the baseline appointment. Each individual's community coordinator explained the study again, this time in more detail and highlighting the commitment to three visits over the oneyear study period; and a second study consent form was reviewed and signed. The participant was given a copy of the informed consent, a study brochure, a flier reminding them of the 3 pending telephone assessment calls, and the expected dates of their 6-month and 1 year follow-up appointments. Each participant was also given a food portion visual handout for reference during the telephone assessments and community coordinator contact information. All study participants completed intervieweradministered assessments which included demographic questions (age, gender, education, occupation, and household data), as well as social support (the Medical Outcomes Study scale) [14], depressive symptoms (the Center for Epidemiological Studies Depression Scale (CES-D) [15], and quality of life (SF-12) questions [16].

The baseline assessment visit also included anthropometric measures (weight, height and waist circumference); two blood pressure readings (ten minutes apart); and a fasting venous blood sample for lipid, glucose, and HbA1c assays. Serum and plasma aliquots were prepared and the buffy coat layer saved. A serum aliquot was sent to the University of Massachusetts Lowell for the lipid profile and a plasma aliquot for the glucose assay; and a frozen whole blood sample (with EDTA) was sent to the Diabetes Diagnostic Laboratory at the University of Missouri for analysis of HbA1c measures. Extra serum and plasma was saved from those who provided informed consent for additional studies.

Three randomly selected 24-hour dietary and physical activity assessments (24 HR) [17] (NDSR-2007 ${ }^{\circledR}$ ) were conducted by trained bilingual Spanish-speaking registered dietitians not involved in the intervention and blinded to participant's condition, via unannounced telephone interviews (on two weekdays and one weekend day) within the following 2 weeks of the assessment visit. Study participants were asked to refer to a food portion visuals booklet they had received at the baseline assessment to facilitate portion size estimation.

At 6 months post-baseline, a measure of weight was scheduled. At one year, the measures collected at baseline were repeated and included demographics, one-year ques- 
tionnaire, Stern predictive equation variables, weight, laboratory measures, and $24 \mathrm{HR}$.

Cash incentives of $\$ 25$ were given at the baseline visit and the 6-month assessment; and $\$ 50$ was given for study completion at the one-year assessment. The Institutional Review Boards of the University of Massachusetts Medical School and Greater Lawrence Family Health Center approved the subject recruitment and data collection procedures. The complete process is outlined in Figure 3.

\section{Randomization and study conditions}

After recruitment and completion of baseline data collection, individuals were randomized to receive the usual care (UC) or to a lifestyle intervention (LI) condition. Randomization occurred at the household level. If any new participant was from the same household as someone already in the study, they were assigned to the same condition already assigned to that household.

\section{Lifestyle intervention}

A group-based intervention (13 group sessions) complemented by 3 individual home visits was developed using principles of social learning theory and patient-centered counseling. The intervention was intended to increase awareness of diabetes prevention strategies, foster positive diabetes prevention attitudes (i.e., self-efficacy) and promote healthy lifestyle behaviors in the target Latino population using literacy-sensitive and culturally-tailored strategies and materials. Dietary targets included increasing whole grains and non-starchy vegetables; and reducing sodium, saturated fat, hydrogenated fats, portion sizes, and the refined carbohydrates and starches predominant in the Latino diet. Participants were encouraged to consume several smaller meals throughout the day instead of one or two larger meals, and to decrease caloric density by increasing volume and satiety with vegetables, fiber, fruit, and water intake. The physical activity goal emphasized walking and recommended that participants increase their overall physical activity by 4000 steps/day or to increase physical activity to one hour per day.

The protocol included nutrition education that focused on traditional Latino foods (emphasizing healthy Latino low-fat and high fiber foods) with hands-on opportunities to learn healthy cooking and food shopping skills, goal setting, self-monitoring, problem-solving, and information on opportunities to engage in physical activity. Intervention materials were tailored to low literacy needs and to the primarily Caribbean Latino culture of the study participants. Materials used included a videotape-novella (soap-opera format) and discussion guide aimed to enhance attitudes toward diabetes prevention (decreasing ambivalence toward lifestyle change, coping with challenges for behavior change); a colorful "food guide" book which classified pictures of frequently consumed Latino and other foods by the colors of a traffic light (green, yellow and red, classified according to saturated or trans-fat content combined with the glycemic index); low-literacytailored goal-setting and self-monitoring worksheets; and food models. All participants were given a pedometer and instructed in its use. Other activities included cooking and consumption of culturally-acceptable meals (at all group sessions), a grocery store tour, and group discussions. Information on safe places for walking and exercise was provided. Significant others (family members or friends living in the participant's household) were invited to attend each group session to elicit home-based support for the implementation of the intervention. Telephone contacts were regularly made to remind participants of group or individual sessions, and to maintain rapport with the participant. At each group session participant goal attainment was reviewed, challenges to adherence were discussed, and solutions were proposed by group participants. Successes by some participants served as models for others. Participants were encouraged to set realistic goals and self-monitor their progress at each session, and were weighed at all sessions. Transportation to sessions was provided as needed.

A manual was developed to guide provider delivery of the sessions. The protocol was implemented by Spanishspeaking community individuals with post high school education and previous training in nutrition. The intervention staff received extensive training in the delivery of the intervention protocol including theoretical background and motivational counseling principles, nutritional and exercise aspects of the intervention, practical strategies to facilitate behavior change, and group management skills. Training involved interactive lectures, role plays and mock sessions aimed at practice of the intervention protocol, and were conducted by the study cardiologist-PI, the behaviorist-co-PI, and the clinical research nutritionist, who also provided ongoing supervision. Booster training sessions were scheduled semiannually.

\section{Baseline results}

Of the 9,959 total telephone screening invitation calls attempted, 2,638 individuals completed a telephone screening call that resulted in 1,296 screening appointments scheduled. The actual number of screening appointments conducted totaled 949 with 391 individuals screening pre-eligible and 312 individuals recruited into the study. The study had proposed recruiting 400 individuals with a $25 \%$ dropout rate resulting in a total of 300 expected participants. The study actually recruited 312 individuals with a lower than anticipated drop-out rate of $7 \%$ resulting in 290 participants at the end of the one-year study intervention period. All individuals chose to complete the study questionnaire in Spanish. 
Baseline characteristics of participants are presented in Table 1 . The study population is primarily female $(74.4 \%)$ with a mean age of 51.9 years old (standard deviation $(\mathrm{SD})=11.3)$. The average BMI was $34 \mathrm{~kg} / \mathrm{m}^{2}$, with $36 \%$ having a sibling with diabetes (18\% of their fathers, $30 \%$ of their mothers had diabetes). Fifty-nine percent had less than a high school education, and only $14.6 \%$ had attended college. Forty-six percent had CES-D of 16 or greater suggesting clinical depression. Mean systolic blood pressure was $128.7 \mathrm{mmHg}$, the mean fasting glucose was $105 \mathrm{mg} / \mathrm{dl}$, and the mean HDL-C was $48 \mathrm{mg} / \mathrm{dL}$. Reported average daily caloric intake was $1553 \mathrm{kcal}, 57 \%$ calories from carbohydrates, $17 \%$ from protein, and $27 \%$ from fat. Percentage of calories from saturated fat was $8.5 \%$ and daily dietary fiber intake was 15 grams. Reported total physical activity expenditure was 28.6 methour/day, only 1.1 met-hour/day was from leisure time physical activity. The mean population risk of developing diabetes in the next 7.5 years was $56 \%$, based on the Stern predictive equation.

\section{Discussion}

The LLDPP established a community-academic partnership to carry out this T2 translational research project. T2 research struggles with human behavior and organizational inertia, infrastructure and resource constraints, and the messiness of proving the effectiveness of interventions aimed at "moving targets" under conditions that investigators cannot fully control [18]. The DPP intervention has been translated into church [19], weight loss clinic [9], and YWCA [20] settings; however we believe this is the first research study that attempts to implement the DPP intervention into a medically underserved Latino community.

There are a number of differences between the LLDPP and DPP. Along the spectrum of translational research, the

\section{Screening \& Recruitment}
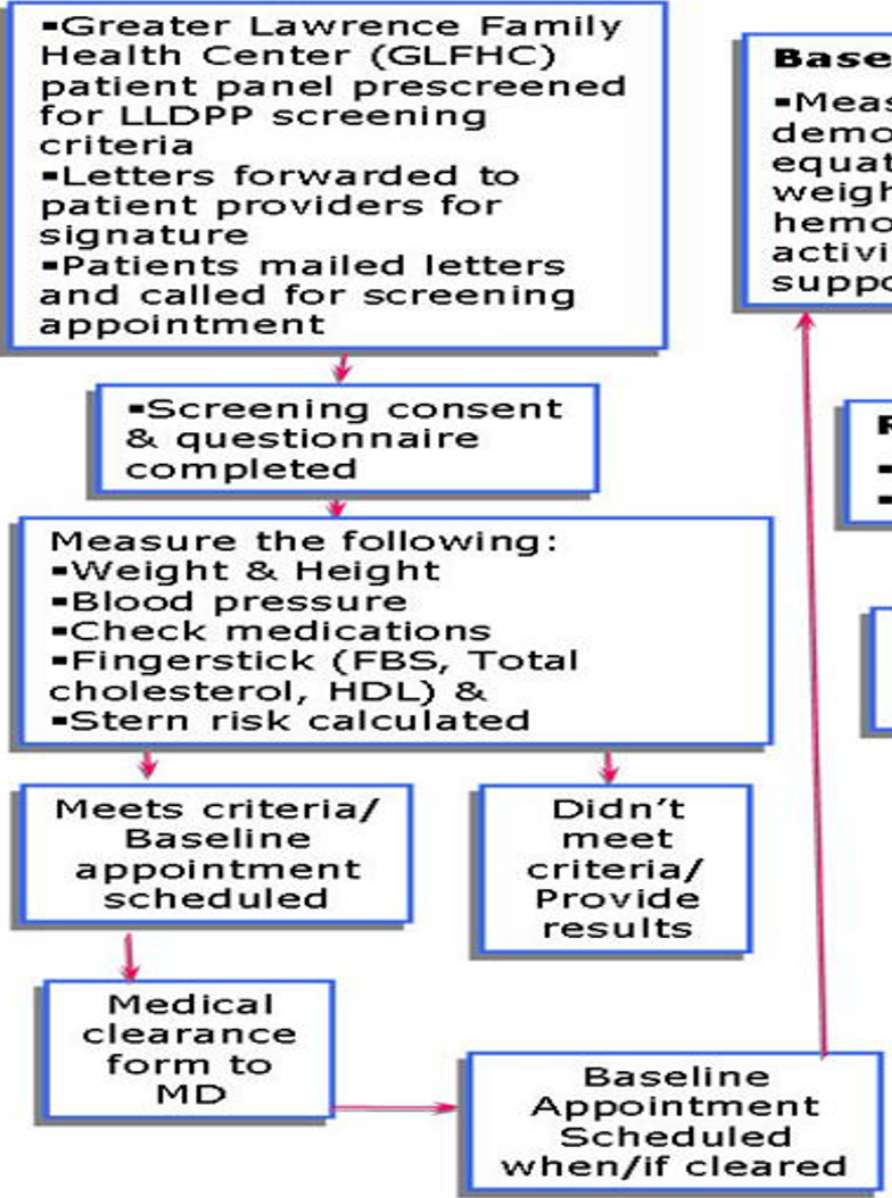

\section{Baseline \& Follow-up}


Table I: Participant baseline characteristics of the Lawrence Latino Diabetes Prevention Project $(\mathbf{N}=3$ I 2)

\begin{tabular}{|c|c|c|c|}
\hline Demographic variables & & $\mathbf{N}$ or Mean & $\%$ or SD \\
\hline \multicolumn{4}{|l|}{ Demographic variables } \\
\hline \multicolumn{4}{|l|}{ Gender $(n=3 \mid 2)$} \\
\hline Male & & 80 & $25.6 \%$ \\
\hline Female & & 232 & $74.4 \%$ \\
\hline Age (years) $(n=3 \mid 2)$ & & 51.9 & 11.3 \\
\hline Body Mass Index $\left(\mathrm{kg} / \mathrm{m}^{2}\right)(\mathrm{n}=3 \mid 2)$ & & 33.9 & 5.6 \\
\hline Normal & & 7 & $2.2 \%$ \\
\hline Overweight & & 62 & $19.9 \%$ \\
\hline Obese & & 243 & $77.9 \%$ \\
\hline \multicolumn{4}{|l|}{ Education $(\mathrm{n}=309)$} \\
\hline Never attended school & & 6 & $1.9 \%$ \\
\hline Some elementary school or high school & & 176 & $57.0 \%$ \\
\hline High school or GED completed & & 65 & $21.0 \%$ \\
\hline Vocational or tech school & & 17 & $5.5 \%$ \\
\hline University or College & & 45 & $14.6 \%$ \\
\hline Smoking in the past 3 months $(n=306)$ & & 35 & $11.4 \%$ \\
\hline \multicolumn{4}{|l|}{ Marital status $(n=307)$} \\
\hline Single & & 62 & $20.2 \%$ \\
\hline Married or Living with Partner & & 159 & $51.8 \%$ \\
\hline Separated, Divorced or Widowed & & 86 & $28.0 \%$ \\
\hline \multicolumn{4}{|l|}{ Employment status $(\mathrm{n}=3 \mathrm{I} \mathrm{I})$} \\
\hline Full-time & & 102 & $32.8 \%$ \\
\hline Part-time & & 41 & $13.2 \%$ \\
\hline Unemployed & & 38 & $12.2 \%$ \\
\hline Disabled & & 76 & $24.4 \%$ \\
\hline Retired & & 23 & $7.4 \%$ \\
\hline Homemaker & & 30 & $9.7 \%$ \\
\hline Volunteer Work & & 1 & $0.3 \%$ \\
\hline \multicolumn{4}{|l|}{ Family history of diabetes or high blood sugar } \\
\hline \multicolumn{4}{|l|}{ Father $(n=297)$} \\
\hline Yes & & 52 & $17.5 \%$ \\
\hline No & & 221 & $74.4 \%$ \\
\hline Don't Know & & 24 & $8.1 \%$ \\
\hline \multicolumn{4}{|l|}{ Mother $(n=297)$} \\
\hline Yes & & 88 & $29.6 \%$ \\
\hline No & & 199 & $67.0 \%$ \\
\hline Don't Know & & 10 & $3.4 \%$ \\
\hline \multicolumn{4}{|l|}{ Sibling $(n=297)$} \\
\hline Yes & & 107 & $36.0 \%$ \\
\hline No & & 185 & $62.3 \%$ \\
\hline Don't Know & & 5 & $1.7 \%$ \\
\hline \multicolumn{4}{|l|}{ Psychosocial variable } \\
\hline \multicolumn{4}{|c|}{ Center for Epidemiological Studies Depression Scale Score $(n=309)$} \\
\hline$<16$ & & 167 & $54.1 \%$ \\
\hline$>=16$ & & 142 & $45.9 \%$ \\
\hline \multicolumn{4}{|l|}{ Anthropometric variables } \\
\hline Fasting Glucose & & 104.98 & 12.11 \\
\hline HDL-C & & 48.02 & 10.37 \\
\hline Systolic Blood Pressure & & 128.7 & 12.35 \\
\hline \multirow[t]{2}{*}{ Stern index ${ }^{a}(n=312)$} & & 0.56 & 0.22 \\
\hline & Mean & SD & \\
\hline Dietary intake $(n=299)$ & & & $\begin{array}{l}\text { Recommended } \\
\text { Values }\end{array}$ \\
\hline Energy intake (kcal/day) & 1553.2 & 584.6 & \\
\hline$\%$ calories from carbohydrates & 56.6 & 8.6 & $45-65 \%$ \\
\hline$\%$ calories from protein & 17.4 & 5.0 & $\sim 15 \%$ \\
\hline
\end{tabular}


Table I: Participant baseline characteristics of the Lawrence Latino Diabetes Prevention Project $(\mathbf{N}=3$ I 2$)$ (Continued)

\begin{tabular}{|c|c|c|c|}
\hline$\%$ of calories from fat & 26.7 & 6.3 & $25-30 \%$ \\
\hline$\%$ of calories from saturated fat & 8.5 & 2.7 & $<7 \%$ \\
\hline Total dietary fiber (g/day) & 15.2 & 7.2 & $\geq 14 \mathrm{~g}$ per $1000 \mathrm{Kcal}$ \\
\hline \multicolumn{4}{|l|}{ Physical activity } \\
\hline Total MET $\dagger-h / d(n=306)$ & 28.6 & 6.3 & \\
\hline Leisure MET-h/d (306) & 1.1 & 1.7 & \\
\hline Occupational MET-h/d $(n=291)$ & 4.6 & 8.6 & \\
\hline Household MET-h/d $(\mathrm{n}=299)$ & 4.4 & 2.9 & \\
\hline
\end{tabular}

a Stern formula a model using age, sex, ethnicity, fasting glucose level, systolic blood pressure, high density lipoprotein (HDL) cholesterol level, waist, and immediate family history of diabetes to predict 7.5-year incidence of diabetes.

†MET_metabolic equivalent task.

DPP was a large-scale efficacy study whereas the LLDPP is a community "effectiveness" intervention study - in an uncontrolled setting and more representative of the real world. The DPP utilized the oral glucose tolerance test as the screening tool, implemented a very intensive one-onone intervention, was very expensive, and recruited a more educated and English-literate population. The LLDPP uses a less demanding Stern predictive equation as the screening tool; a culturally-adapted, primarily groupbased, less-expensive intervention; a less educated study population; and conducts the project entirely in Spanish with all tools designed for oral administration in a population with a high rate of illiteracy in both English and Spanish.

Community-based research presents many unique challenges and requires different research skills to implement and evaluate interventions in real-world settings. A decade ago Israel and colleagues presented a synthesis of key principles of community-based research and explored the major challenges to such research [21]. Principles of practice for academic-practice-research partnerships were also described at that time [22]. More recently, Plowfield and colleagues published critical aspects necessary for effective partnerships between academic institutions and community health agencies that included a commitment up front to time, tactful communication, talented leaders and mutual trust [23].

The LLDPP community-academic partnership took considerable amount of time to establish, and started with the partnership of the GLFHC and UMMS. By housing one of the CDC-sponsored Racial and Ethnic Approaches to Community Health (REACH) projects, the GLFHC had gained experience from the implementation of the REACH 2010 project in Lawrence that was instrumental to the start-up of the LLDPP, and had already developed a good research infrastructure in the Lawrence community which may have enhanced trust on the part of the community. As well, trusted, talented community leaders from the REACH 2010 Latino Health Coalition (YWCA and LCOA/ Senior Center) were involved in leading the LLDPP com- munity-academic partnership, and were instrumental to the study's success both in planning the recruitment design, and devoting the skilled staff. Recruitment and follow-up went exceptionally well because of the talent and dedication of the community coordinators and the clinic assistant, all Lawrence Latinas who enjoyed immediate credibility and trust because they were known and familiar in the settings they worked. Additionally, basing the study at the Senior Center gave it a significant presence and visibility in the community. Communication was maintained through innumerable visits, open communication, and regular, active participation in the clinics at the Senior Center by the project director; a collaborative relationship between the project director and the community-PI; monthly team meetings; and regular (thrice yearly) meetings of the Community Advisory Committee which included all study staff, the community leaders, and the academic investigators, under the leadership of an open, engaged, and community-responsive PI.

The DPP was successfully translated to a Latino community utilizing a community-academic partnership. Although the final outcomes remain to be analyzed, the process of translation appears to work. The LLDPP recruited patients at risk of diabetes using a predictive equation (which saved time and money compared to the oral glucose tolerance test), and carried out the intervention and study assessments completely in Spanish, with a remarkable retention rate of $93 \%$. This was largely due to the community-academic partnership that was formed and the ongoing sensitivity to the needs of the Lawrence Latino community.

\section{Competing interests}

The authors declare that they have no competing interests.

\section{Authors' contributions}

IO, TT, MR, BO and PM participated in conception, and design of the study. IO, PM, TT and BO participated in conducting the study. IO, PM, TT, MR, BO, YM and SP drafted or critically revised the manuscript and IO, PM, 
TT, MR, BO, YM, and SP read and approved the final manuscript.

\section{Acknowledgements}

The project described was made possible by Grant Number R 18 DK067549 from the National Institute of Diabetes and Digestive and Kidney Diseases (NIDDK). Its contents are solely the responsibility of the authors and do not necessarily represent the official views of the NIDDK. We would like to acknowledge the study team made up of Martha Medina, Minerva Grullon, Jael Castillo, Annabella Aguirre, Lizette Jaco, Martha Cruz, Yenith Morantes and Alison Kieley for without their expertise and dedication this study would not have been possible. We thank the community agency directors for their invaluable support: Vilma Lora and Mary O'Neill of the YWCA; Martha Velez and Bernard Reilly of the LCOA/Senior Center; Milagro Grullón of the City of Lawrence; and Dr. G. Dean Cleghorn of the Greater Lawrence Family Health Center. We would also like to thank: Robert Magner and his colleagues in the UMass Medical School's Biostatistics Research Group for their statistical expertise; Dr. Patty Freedson from University of Massachusetts-Amherst for her assistance with the physical activity assessment; Drs. Robert Nicolosi, Garry Handlemann and Thomas Wilson for the biological measurement expertise from the University of Massachusetts-Lowell; Dr. Glennon O'Grady and the GLFHC providers for their ongoing support of the project; and the fine people of Lawrence, Massachusetts.

\section{References}

I. Caballero AE: Diabetes in the Hispanic or Latino population: genes, environment, culture, and more. Current Diabetes Reports 2005, 5:2 17-25.

2. Centers for Disease Control and Prevention: Prevalence of diabetes among Hispanics - selected areas, 1998-2002. MMWR Morb Mortal Wkly Rep 2004, 53:94I-4.

3. Hill JO, Wyatt HR, Reed GW, Peters JC: Obesity and the environment: where do we go from here? Science 2003, 299:853-5.

4. Kuczmarski R, Flegal K, Campbell S, Johnson C: Increasing prevalence of overweight among US adults. The National Health and Nutrition Examination Surveys, 1960 to 1991. JAMA 1994, 272:205-II.

5. Narayan KMV, Boyle JP, Thompson T], Sorensen SW, Williamson DF: Lifetime risk for diabetes mellitus in the United States. JAMA 2003, 290: 1884-90.

6. Knowler WC, Barrett-Connor E, Fowler SE, Hamman RF, Lachin JM, Walker EA, Nathan DM, Diabetes Prevention Program Research Group: Reduction in the incidence of type 2 diabetes with lifestyle intervention or metformin[see comment]. New England Journal of Medicine 2002, 346:393-403.

7. Rubin RR, Fujimoto WY, Marrero DG, Brenneman T, Charleston JB, Edelstein SL, Fisher EB, Jordan R, Knowler WC, Lichterman LC, Prince M, Rowe PM, DPP Research Group: The Diabetes Prevention Program: recruitment methods and results. Controlled Clinical Trials 2002, 23:157-7I.

8. Eddy DM, Schlessinger L, Kahn R: Clinical outcomes and costeffectiveness of strategies for managing people at high risk for diabetes[see comment][summary for patients in Ann Intern Med. 2005 Aug 16; 1 43(4):122; PMID: 16 103465]. Annals of Internal Medicine 2005, I 43:25 I-64.

9. Pagoto SL, Kantor L, Bodenlos JS, Gitkind M, Ma Y: Translating the diabetes prevention program into a hospital-based weight loss program. Health Psychology 2008, 27:59I-8.

10. Stern MP, Williams K, Haffner SM: Identification of persons at high risk for type 2 diabetes mellitus: do we need the oral glucose tolerance test?[see comment][summary for patients in Ann Intern Med. 2002 Apr 16;136(8):129; PMID: I 1 955045]. Annals of Internal Medicine 2002, I 36:575-8I.

II. Silka L, Cleghorn GD, Grullon M, Tellez T: Creating CommunityBased articipatory Research in a Diverse Community: A Case Study. Journal of Empirical Research on Human Research Ethics 2008, 3:5-16.
12. Rosal MC, Ebbeling CB, Lofgren I, Ockene JK, Ockene IS, Hebert JR: Facilitating dietary change: the patient-centered counseling model. Journal of the American Dietetic Association 200I, 101:332-41.

13. Rosal MC, Goins KV, Carbone ET, Cortes DE: Views and preferences of low-literate Hispanics regarding diabetes education: results of formative research. Health Education \& Behavior 2004 3I:388-405.

14. Sherbourne $C D$, Stewart AL: The MOS social support survey. Soc Sci Med I991, 32:705-14.

15. Devins G, Orme C: Center for Epidemiologic Studies Depression Scale. In Test Critiques Edited by: Sweetland R. Kansas City: Test Corp of America, a subsidiary of Westport Publishers, Inc; 1985: | 44-60.

16. Ware J, Kosinski M, Keller S: A I 2-Item Short_Form Health Survey: Construction of scales and primarily tests of reliability and validity. Medical Care 1996, 34:220-33.

17. Matthews CE, Freedson PS, Hebert JR, Stanek EJ 3rd, Merriam PA, Ockene IS: Comparing physical activity assessment methods in the Seasonal Variation of Blood Cholesterol Study. Medicine \& Science in Sports \& Exercise 2000, 32:976-84.

18. Woolf $\mathrm{SH}$ : The meaning of translational research and why it matters. JAMA 2008, 299:2II-3.

19. Boltri JM, Davis-Smith YM, Seale JP, Shellenberger S, Okosun IS, Cornelius ME: Diabetes prevention in a faith-based setting: results of translational research. Journal of Public Health Management \& Practice 2008, 14:29-32.

20. Ackermann RT, Marrero DG: Adapting the Diabetes Prevention Program lifestyle intervention for delivery in the community: the YMCA model. Diabetes Educator 2007, 33:69.

21. Israel BA, Schulz AJ, Parker EA, Becker AB: Review of communitybased research: assessing partnership approaches to improve public health. Annual Review of Public Health 1998 , 19:173-202

22. Baker EA, Homan S, Schonhoff R, Kreuter M: Principles of practice for academic/practice/community research partnerships. American Journal of Preventive Medicine 1999, 16:86-93.

23. Plowfield LA, Wheeler EC, Raymond JE: Time, tact, talent, and trust: essential ingredients of effective academic-community partnerships. Nursing Education Perspectives 2005, 26:217-20.

\section{Pre-publication history}

The pre-publication history for this paper can be accessed here:

http://www.biomedcentral.com/1471-2288/9/20/prepub

Publish with BioMed Central and every scientist can read your work free of charge

"BioMed Central will be the most significant development for disseminating the results of biomedical research in our lifetime. "

Sir Paul Nurse, Cancer Research UK

Your research papers will be:

- available free of charge to the entire biomedical community

- peer reviewed and published immediately upon acceptance

- cited in PubMed and archived on PubMed Central

- yours - you keep the copyright

Submit your manuscript here:

http://www.biomedcentral.com/info/publishing_adv.asp

BiolMedcentral 